\title{
NERUDA: \\ CON LA PERSPECTIVA DE 25 AÑOS
}

JOSÉ CARLOS ROVIRA

El 23 de septiembre de 1973 Pablo Neruda moría en un hospital de Santiago de Chile después de una larga enfermedad y en medio de unos días de terror en su país, terror abierto por el golpe de estado perpetrado el $11 \mathrm{de}$ septiembre por el general Pinochet y el fascismo chileno. Pablo Neruda, un poeta que había adquirido la condición de testigo de la historia contemporánea, protagonista tantas veces de la misma, moría en unas fechas de cierre de la misma historia, con la reflexión y la conciencia de lo que estaba ocurriendo. Sus memorias Confieso que be vivido trazaban la reflexión final sobre aquellos días y aquel acontecer.

Han pasado poco más de 25 años desde todo aquello y no es necesario advertir que esta misma semana aquella historia sigue siendo actual ${ }^{1}$. Por una coincidencia abrimos hoy un coloquio sobre Pablo Neruda «con la perspectiva de 25 años», un coloquio que quiere ser sobre todo una reflexión sobre la vigencia de un poeta que escribió miles de páginas de poesía, entre las que encontraremos con seguridad algunas que están indisolublemente unidas a nuestra memoria y a la memoria del siglo. Es en esa dirección, y en el terreno de la poesía, por lo que hemos invitado a un grupo reducido de estudiosos entre los que están algunas de las figuras más representativas de la crítica nerudiana e hispanoamericana.

Los encuentros que realizamos surgen entonces como parte de una reflexión sobre la poesía que quiere entender de todos los aspectos que la obra abundantísima de Neruda plantea. Sabemos que un poeta con una amplitud de escritura que nos hace contar más de cuarenta libros tiene todas las posibi- lidades de ser leído desde diferentes perspectivas. Sabemos también que la determinación social y política de una parte de la obra de Neruda ha creado fuertes condicionantes en algunos lectores que han preferido optar por el camino más fácil: el de la reducción de Neruda a una parte de su obra y, en tiempos de descrédito de la poesía social, el intento de arrumbamiento de Neruda en el desván de las cosas viejas del siglo.

Pero un poeta que se constituyó como tal a través de múltiples núcleos temáticos (la poesía amorosa, la metafísica residencial, el lenguaje de las cosas elementales, el mito y la historia latinoamericana, etc.) es un poeta al que difícilmente se le podrá arrumbar mediante una descalificación, porque Pablo Neruda a través de varias escrituras fue sobre todo un formador de lenguajes imprescindibles en la dimensión de nuestra lengua y nuestro siglo. El Premio Nobel obtenido en 1971 fue sobre todo el reconocimiento de una universalidad que lo había convertido en una de las voces más sobresalientes de nuestro tiempo. La Academia Sueca en su dictamen decía: «El Premio Nobel de Literatura de este año ha sido adjudicado a un contencioso autor que no sólo es discutido sino que, para muchos, es también discutible. Esta discusión se ha mantenido durante los últimos cuarenta años, lo cual prueba que su contribución es incuestionable y que, además, esta discusión se ha debido al valor artístico de la obra», para pasar a resaltar la abundancia de la producción de Neruda en los siguientes términos: «El motivo por el cual la inventiva de la poesía nerudiana se ha pegado a nuestros oídos se debe a que su masa es avasalladora. Así es que nos podemos preguntar si es El coloquio se realizó entre el 22 y 24 de marzo de 1999. Era una semana de espera sobre la solicitud de extradición de Pinochet que la Cámara de los Lores británica dictaminó favorablemente por segunda vez el día 24 de marzo.
Neruda: con la perspectiva de 25 años INTRODUCCIÓN 
que existe algo igual en la historia de la poesía [...] Que toda esta producción literaria se encontrara a un mismo nivel, sería sencillamente inconcebible. Quien desee encontrar el flanco débil en la poesía nerudiana no necesita buscarlo mucho tiempo. Quien desee encontrar el flanco fuerte no necesita buscarlo en absoluto. Desde su primer triunfo literario y hasta su última obra, casi podemos decir que lo encontramos en una riqueza inagotable».
Bien, desde estos presupuestos, veinticinco años después de la muerte del poeta, nos gustaría que estos días sirviesen, no tanto para seguir buscando flancos débiles o fuertes, sino para trazar lo que parece una pregunta o una afirmación obligada: «Neruda, poeta para el siglo XXI».

Agradecemos otra vez — son varios agradecimientos ya en encuentros similares-, a la Caja de Ahorros del Mediterráneo la financiación y el auspicio de este encuentro. 